\title{
Religion, Evolution, and the Basis of Institutions: The Institutional Cognition Model of Religion
}

\author{
Connor Wood and John H. Shaver
}

\begin{abstract}
Few outstanding questions in the human behavioral sciences are timelier or more urgently debated than the evolutionary source of religious behaviors and beliefs. Byproduct theorists locate the origins of religion in evolved cognitive defaults and transmission biases. Others have argued that cultural evolutionary processes integrated non-adaptive cognitive byproducts into coherent networks of supernatural beliefs and ritual that encouraged ingroup cooperativeness, while adaptationist models assert that the cognitive and behavioral foundations of religion have been selected for at more basic levels. Here, we survey these differing approaches, noting their respective strengths and weaknesses. We then advance a novel model that centers on the ability of language to generate alternative worlds independent of immediate empirical facts, and thus highlight the similarities between religious belief and the modes of cognition that underlie institutions in general. The institutional cognition model of religion accounts for some of the shortcomings of extant approaches and draws attention to the human ability to create non-empirical worlds; that is, worlds that are imaginary. Both religious beliefs and institutional facts—such as jurisdictional borders-are non-empirical assertions, yet they are socially accepted as truths and reified through ritual and behavior. One type of non-empirical, linguistically generated belief—supernatural agent belief-is particularly effective for stabilizing systems of arbitrary norms by rooting them in deontic rather than utilitarian reasoning. The evolutionary roots and continued persistence of religion are thus functions of the capacity for humans to generate cognitive alternatives to empirical reality, and the need to stably coordinate those alternative conceptions.
\end{abstract}

Keywords: religion, evolution, cognition, transcendental social, institutional facts, byproduct theories, cultural evolution, supernatural beliefs, norms

\section{INTRODUCTION}

Religions are among the most complex, most consequential, and least understood of all human social phenomena. From the smallest ancestor cults to the largest world traditions, religions motivate powerful attachments and group allegiances (Ginges and Hansen 2010), shape affective commitments (Sibley and Bulbulia 2014), and have consistently influenced the course of human history (Bellah 2011). Religious beliefs soothe individual fears and anxieties (Vail et al.
2010) and motivate obedience to norms (Shariff et al. 2016), religious rituals forge social bonds (Mogan, Fischer, and Bulbulia 2017) and signify commitments to parochial obligations (Rappaport 1999; Sosis and Bressler 2003), while religious identity often drives intractable conflicts (Atran and Ginges 2012; Gómez et al. 2017) and anchors ethnic loyalties (Berns et al. 2012). Yet although religion is critically tied to the most fundamental human social dynamics, and despite centuries of theoretical speculation (e.g., Hume [1779] 2007; Nietzsche [1887] 
1998; Durkheim [1912] 2008), much about the nature of religion-including its evolutionary origins - remains unresolved.

Over the past 30 years, a growing research community in the cognitive, behavioral, and evolutionary sciences has begun to address the origins and functions of religion as a universal human phenomenon-one that varies radically in expression from culture to culture, but which yet retains similar core features worthy of, and amenable to, systematic examination (McNamara, Sosis, and Wildman 2011). The overall explanatory framework for these developing research programs in the sciences is an evolutionary one, rooted in the neo-Darwinian synthesis. Though these researchers all share a commitment to using evolutionary insights to explain the emergence and general features of religion, this has not been a unified effort. Instead, there have been three relatively distinct evolutionary approaches to religion, each with different assumptions, foci, and methodological preferences (Sosis and Bulbulia 2011; Shaver et al. 2016).

The earliest evolutionary approaches to religion were those that treated supernatural beliefs as emerging from cognitive modules that solved adaptive problems in ancestral human environments. Importantly, although originally emerging as functional solutions to pressing social and environmental issues, the cognitive modules responsible for religion did not emerge from selection for religion. Instead, theorists in this camp contend that religion naturally emerged as a cognitive byproduct of the human mind. Another group of theorists began with this byproduct approach to religion, but extended this model to contend that some religious beliefs that emerged over the course of human evolution were more effective at promoting cooperation than others, and that those religions that more effectively cultivated cooperative affordances came to dominate the contemporary religious landscape. In other words, some religions, through processes of cultural evolutionary group selection, spread at the expense of other, less successful religions. Finally, a third, albeit smaller, group of scholars, focused more on ritual than on belief, hypothesized that the core features of religions - in and of themselves-may be biologically adaptive, insofar as they provide reliable mechanisms for the communication of in-group commitments. Here we detail each of these approaches, and their major strengths and weaknesses.

One of the most consequential and longstanding debates within the evolutionary sciences of religion pits adaptationist models against byproduct models for the evolution of religious capacities. This debate has often proved unproductive, however, and as a result several thinkers have recently called for a move beyond simplistic adaptationist-versus-byproduct discourse (Purzycki et al. 2014; Shaver et al. 2016; Sterelny 2017). Thus, after our initial review, we describe a model for the evolutionary origins of religious phenomena that extends current theories by accounting for the social and apparently functional aspects of religions, as well as for beliefs in supernatural agents (e.g., gods and spirits) as expected individual-level ancillaries to the social and cognitive processes that produce human institutions. In particular, these processes center on the ability to maintain different mental representations at the same time (Taves 2015) and to conform behavior to representations that are socially generated rather than empirical in nature. This model helps to account for the cognitive underpinnings of the complex imaginal content of religions, a topic that evolutionary approaches to religion have often overlooked (Bloch 2008).

\section{BYPRODUCT THEORIES OF THE EVOLUTION OF RELIGION}

As a contemporary research program, the cognitive byproduct account for the evolution of religion emerged from the work of scholars such as Stewart Guthrie (1995) and Pascal Boyer (2001; Boyer and Liénard 2006), among others (Lawson and McCauley 1993; Atran 
2002; Barrett 2004; Whitehouse 2004). These thinkers drew on theories of cognitive modularity (Fodor 1983), and later the assumptions of evolutionary psychology (Barkow et al. 1995; see Sosis, 2017) to posit that the apparent ubiquity of religious belief is due to a native "fit" between certain innate features of the human mind and the most successful supernatural concepts. Guthrie's work, itself informed by the work of the anthropologists Robin Horton (1967) and E. B. Tylor (1870), suggests that religious beliefs are the result of the over-application of innate, evolved teleological intuitions and perceptual biases to the nonhuman world, and the consequent imputation of person-like traits to natural phenomena. In short, "religion is anthropomorphism" (1995, 178). Guthrie's theory, like all byproduct theories, focuses on the ways that proto-religious and supernatural concepts spontaneously emerge from normal human cognitive processes that evolved to solve ancestral problems unrelated to religion.

Expanding on this line of reasoning, Justin Barrett (2000) posited a "hyperactive agency detection device," or HADD, as an explanation for the origins of religious beliefs. The HADD is a cognitive module which evolved to scan the environment for signs of agency, such as twigs breaking in nearby woods, in order to alert an individual to opportunity or danger. Because fellow agents are key sources of both danger and of aid, they are profoundly relevant for fitness, and, as such, our brains evolved to be hypersensitive to cues of agency. As a result, the default calibration of the human mind produces more false positive alarms than false negatives. In other words, it is better to wrongly impute, say, an imaginary tiger in the nearby bushes than to fail to identify a real one (e.g., McCauley and Lawson 2002). Equipped with the HADD, the reasoning goes, human minds can scarcely avoid coming up with supernatural agent beliefs, since they are incessantly scaring up thoughts of invisible agents. Much subsequent work in the cognitive science of religion has built on Guthrie's and Barrett's ideas about the cognitive naturalness and spontaneity of supernatural agent beliefs (Atran 2002; Atran and Henrich 2011; McCauley 2013).

By contrast, Boyer's (1994; 2001) work emphasizes the epidemiology of religious ideas, or how and why they spread through, and attain fixity within, populations. Drawing on the 'epidemiology of representations' approach of Dan Sperber (1985; 1996), Boyer posits that some ideas, particularly those that are "minimally counterintuitive" (MCI) violations of folk epistemologies, are cognitively appealing, and thus are more likely to spread. Similar to the work of Guthrie and Barrett, the folk intuitions that make some ideas more appealing than others did not evolve to produce religious representations. Instead, folk intuitions evolved to make adaptive inferences about the physical and social world. Unlike Guthrie's and Barrett's theories, however, the MCI theory is not principally a theory of the emergence of religious beliefs, but rather an attempt to explain their remarkable diffusion and persistence across populations as a function of the "susceptibility" of human minds to counterintuitive representations.

Although they build on distinct theoretical underpinnings and have different explanatory aims, the HADD and MCI theories have become conceptually integrated in much research in the cognitive science of religion. Broadly, this research program conjectures that hyperactive agency detection and minimal counterintuitiveness, along with cognitive biases toward teleological thinking (Kelemen 2004), anthropomorphic thought (Barrett and Keil 1996), and mind-body dualism (Bloom 2005) as well as theory of mind capabilities (Premack and Woodruff 1978) all contribute to the human tendency for religious cognition (Atran, 2002; Atran and Henrich, 2011; Barrett and Lanman 2008). However, empirical evidence in support of byproduct hypotheses is often mixed and difficult to interpret (e.g., Purzycki and Willard 2016). Boyer and Ramble (2001) and Barrett and Nyhof (2001) found that research subjects were better able to recall 
content from stories that contained domainlevel intuitive violations than those that did not. Other research has extended these findings to real-world cultural items, finding (for instance) that popular folktales better fit the MCI profile than obscure folktales (Norenzayan et al. 2006). Yet some predictions of MCI theory have been less well supported. For example, MCI concepts were found to require more processing time to understand than non-MCI concepts, but this difference in processing time did not account for differential recall of MCIs (Harmon-Vukić et al. 2012). Meanwhile, theoretical work has not satisfactorily established how counterintuitive concepts should be parsed from counter-schematic concepts (concepts that violate cultural semantic schemas that are not rooted in evolved intuitions) (Purzycki and Willard 2016). MCI theory, moreover, does not adequately specify why specifically religious or supernatural concepts should be selectively transmitted and retained over, say, memorable jokes or stories (Purzycki 2010; Willard 2017).

Empirical support for the HADD hypothesis and its relatives also suffers from ambiguity. It is relatively clear that cognitive biases have some positive relationship to religious belief, but the nature of that relationship is open to interpretation. Human minds do indeed exhibit cognitive biases toward promiscuous teleology, intuitive mind-body dualism, and the over-imputation of intentional agency (Barrett 2000; Kelemen 2004; Banerjee and Bloom 2014), and studies have found that variation in these biases predicts religious belief (Willard and Norenzayan 2013). However, one recent large study of religious believers and atheists in Eastern Europe reported that individual-level variances in cognitive biases were much less important for predicting belief in God than external cultural and socialization factors (Willard and Cingl 2017).

Another body of empirical findings widely cited in support of byproduct hypotheses builds on dual-process models of cognition (e.g., Evans 2010; Kahneman 2013) to demonstrate that people with more intuitive cognitive styles are more likely to be religious, and to believe in supernatural beings, than those with more analytic styles (Shenhav, Rand, and Greene 2012; Pennycook et al. 2016). Theorists have cited these findings to support the contention that religious belief emerges naturally from intuitive cognitive defaults and biases, and only recedes when analytic or reflective cognition effortfully challenges those biases (McCauley 2013; Willard and Norenzayan 2013). However, this relationship may be confounded by other associations, such as that between analytical thinking and individualism. Religious believers tend to have more interest in social relationships than atheists do (Bainbridge 2005; Caldwell-Harris 2012), and sociality and collectivism are positively correlated with holistic and non-analytical cognition (Talhelm et al. 2014). Dual-process findings therefore may offer only qualified support for byproduct theories of religion.

\section{CULTURAL EVOLUTIONARY AND GROUP SELECTION MODELS OF RELIGION}

Another approach to the scientific study of religion builds on modular byproduct theories, but augments them using cultural evolutionary theory (Atran and Henrich 2011; Gervais et al. 2011; Norenzayan et al. 2016). Cultural evolutionary theorists generally concur with byproduct theorists that religious beliefs and institutions are based on cognitive hardware whose original adaptive function was not related to religion. Yet a cultural evolutionary approach to religion helps, in part, to solve the "Mickey Mouse problem." The cartoon character Mickey Mouse precisely matches the characteristics expected for an intuitively appealing religious belief under byproduct models: Mickey is an agent with intentions, yet he violates some basic intuitive ontological categories. But we do not worship Mickey Mouse as a god, and indeed we do not "believe" in him at all (Henrich 2009; Gervais et al. 2011). Similarly, the so-called "Zeus problem" highlights the fact that many deities match the intuitive cognitive profiles 
of successful gods, yet most people worship only one or a few gods (Gervais and Henrich 2010). Cultural evolutionary theories address these problems by positing that cognitive "fit" is necessary but not sufficient for the transmission and retention of supernatural concepts, and that context biases instead are required to facilitate the preferential transmission of particular religious concepts over others (Henrich 2009). These postulates dovetail with certain cognitively oriented solutions to the same problems, such as Atran's (2002) argument that integrating cognitive theories with "commitment" theories of religion (see below) could account for motivational factors that might discriminate between mere fantasy or imagination and genuinely held religious belief.

Context biases are evolved cognitive predispositions to preferentially learn from some people or contexts rather than others (Boyd and Richerson 1988). For example, Henrich and Gil-White (2001) suggested that humans are evolutionarily predisposed to attend to and learn from high-prestige others, such as respected elders. Thus, religious beliefs espoused by high-prestige exemplars should spread and evoke more commitment than beliefs espoused by others. In general, cognitive byproduct theories of religion rely heavily on content biases to argue that some ideas enjoy a transmission advantage because they better fit the human mind's innate architecture, while cultural evolutionary theories of religion assert that many ideas and practices are transmitted primarily because of the prestige, presumed competence, or in-group membership of the people doing the transmitting (Norenzayan et al. 2016). In principle, context biases thus enable cultural evolutionary models to take account of widespread cultural variation in religious forms and concepts.

Cultural evolutionary models additionally posit that some form of selection pressure operates on religious groups, such that those with configurations of beliefs and practices that successfully sustain cooperation and communal norms in their host populations are more likely to survive over the long term (Atran and Henrich 2011; Norenzayan et al. 2016). Over the course of millennia, the cognitively natural byproducts that give rise to religious concepts have thus been yoked into service in a variety of ways to facilitate ever-greater levels of cooperation within groups, leading to the efflorescence of world religions whose morally concerned, punishing deities encourage (and enforce) prosocial norms and in-group altruism (Norenzayan 2013; Purzycki et al. 2016). Evidence for this hypothesis is found in a growing body of studies that document a positive (if not unambiguous) correlation between the size and complexity of societies, the presence of morally concerned, punitive deities, and disinterested prosocial economic cooperation (Johnson 2005; Botero et al. 2014; Watts et al. 2015; Purzycki et al. 2016).

One well-known example of a selective process postulated to have culture-level effects is the use of ritual to influence observers' receptivity to religious claims. Ritual behaviors may function as "credibility-enhancing displays" (CREDs), leveraging social learning and context biases to increase the perceived plausibility of otherwise empirically unprovable claims (Henrich 2009; Lanman and Buhrmester 2017). For instance, parents who pray before meals and attend church are indicating that they take belief in God seriously enough for that belief to influence their behavior. The CREDs hypothesis predicts that children of such parents will be more inclined to take belief in God seriously themselves, compared with children whose parents, although claiming to believe, do not perform any actions that would be expected if those beliefs were genuine. This argument accords with discussions within the sociology of religion regarding the ways in which religious traditions deploy ritual performance to support the perceived plausibility of their claims (see, e.g., Berger 1969). In line with Henrich's assertion, research has found that exposure to CREDs is a much stronger predictor of religious beliefs than cognitive biases alone (Lanman and 
Buhrmester 2017; Maij et al. 2017; Willard and Cingl 2017), although this effect may be driven in particular by early-life exposure to CREDs (Turpin, Andersen, and Lanman 2018). At the level of groups, though, such findings may conceal a tautology, since they essentially demonstrate that cultural differences produce cultural differences (see Bidney 1944).

Explicit group selection models (e.g., E. O. Wilson 2013) are another, bolder, and more controversial step beyond cultural evolutionary models (although in actual practice the category distinction between them is not always sharp). David Sloan Wilson, the best-known proponent of group selection (or "multilevel selection"; see Sober and Wilson 1999) as an explanation for the evolution of religion, has argued (2002) that religion is the product of evolutionary selection between groups, and that religious beliefs and behaviors have gradually developed as tools for uniting human groups and increasing their social coherence, cooperativeness, and reproductive success. Similarly, Martin Nowak has used mathematical modeling to support group selection scenarios for the evolution of cooperative institutions in human society, including religion (Nowak and Coakley 2013). Group selection is a controversial concept in evolutionary biology (Nowak, Tarnita, and Wilson 2010; Abbot et al. 2011), and space limitations prevent us from seriously examining the debates surrounding it here. However, group selection models have played an important role in recent evolutionary discourse on the origins and functions of religion (Haidt 2012), and, as described above, cultural evolutionary models themselves often rely heavily on group selection dynamics (Davis 2015).

\section{ADAPTATIONIST MODELS OF THE EVOLUTION OF RELIGION}

According to both byproduct and most cultural evolutionary theories, religious beliefs and behaviors are fundamentally grounded in cognitive capacities that evolved under selection pressures unrelated to religion. They are thus not adaptations in their own right, although cultural evolution theorists posit that they have become enmeshed in social institutions and selection dynamics at the cultural level. A third research strand, however, argues that at least some religious phenomena have likely resulted from adaptations in their own right or that, over the course of human evolutionary history, religious traits have stabilized into a functional complex (D. S. Wilson 2002; Alcorta and Sosis 2005; Bulbulia 2008; Sanderson 2008; Sosis 2009; Purzycki and Sosis 2010). The adaptationist program in the evolutionary study of religion largely focuses on the benefits and costs of interpersonal or in-group cooperation and coordination, such as stabilizing group commitments and norms (Irons 2001; Sosis and Bressler 2003). It may appear odd prima facie to look for adaptationist explanations for a phenomenon that seems so manifestly wasteful—after all, the immense amounts of time, energy, and resources humans invest into religious institutions and ceremonies do not directly produce food or build shelter. If anything, then, religious behaviors would seem to decrease fitness! But adaptationists argue that there are good reasons, both logical and empirical, to believe that these costs are precisely what makes religion functional.

Costly signaling theory offers one framework for understanding this relationship (Irons 2001; Sosis 2005). In biology, costly signaling theories address the problem of how communicative signals, such as signals of cooperative intent between animals, can be trustworthy even when there is strategic incentive for deception (Grafen 1990; Zahavi and Zahavi 1999). Strategic "costs"- also known as "handicaps" are thought to make sending the signal more difficult for lower-quality signalers, reducing their incentive to attempt deceptive signaling and ensuring that the signal remains generally reliable. Importantly, in the animal world communicative signals often take the form of ritualized behavioral patterns (Maynard Smith and Harper 2004). In the context of religion, costly 
signaling theorists posit that cultural and religious rituals serve a similar function, by raising the cost of belonging to the religious community to the point that only the truly committedthat is, those who genuinely accept the supernatural and ethical propositions that define the community-find it worthwhile to participate in them (Sosis 2003). Costly religious rituals and requirements thereby ensure a high internal level of cohesion and commitment within religious social networks, and are able to provide benefits, such as shared resources or practical information, to their members (Iannaccone 1994). As such, costly signaling is construed as a solution to the "free-rider problem" that plagues many collective action efforts, by filtering out potential members who might attempt to piggyback on the community's resources without contributing in return.

Empirical tests of the costly signaling theory of religion have largely produced supportive findings. For example, in a well-known retrospective study of nineteenth-century American communes, Sosis and Bressler (2003) found that religious communes with more ritual costs lasted significantly longer than those with fewer costs, and religious communes of all kinds outlived their secular counterparts. Studies of contemporary denominations have corroborated these results, finding that stricter, more costly religious communities fare better demographically than less-strict communities (Olson and Perl 2001; Scheitle and Fincke 2008). One of us (Wood) has recently found that growth among American Protestant denominations over three decades was significantly predicted by the prevalence of ritual practices, such as prayer and scripture study, among congregants (Wood et al., under review). Costly religious signaling also correlates with relevant outcomes at the individual level. In rural India, villagers who participate intensively in religious rituals are seen as more trustworthy and committed across a variety of social domains (Power 2017). In another well-known study, higher levels of experienced pain subsequently predicted more generosity among Mauritians participating in an extreme ritual (Xygalatas et al. 2013). Similarly, costly ritual practices in Brazilian Candomblé are associated with higher levels of generosity and cooperation between individuals (Soler 2012). Yet despite apparently supportive empirical evidence, costly signaling models of religion suffer from some conceptual problems. For example, signaling theorists expect that the return on the production of signals is increased fitness (e.g., Irons, 2001). However, fitness is notoriously difficult to assess, since it must be calculated over an individual's lifetime (Laland and Brown 2002). Moreover, it is not always clear how best to measure costs in human cultural contexts, in particular since costly signaling theorists tend to rely on subjective or perceived estimates of ritual's costs and benefits (Murray and Moore 2009).

While commitment costs and rituals are important for understanding religion under an adaptationist framework, supernatural beliefs are also thought to be a central feature of religions. Importantly, supernatural beliefs motivate participation in rituals and rationalize social norms (Purzycki and Sosis 2010). Indeed, communes in the nineteenth century that lacked religious beliefs were equally likely to fail regardless of their costliness (Sosis and Bressler 2003). This observation offers an important point of contact between costly signaling theory and the CREDs hypothesis, since both propose that "actions speak louder than words," yet entail the existence of some underlying commitment worth signaling or partaking in ritual for.

Adaptationist approaches, in general, place a greater focus on phenotypes than on the underlying cognitive and genetic processes that motivate behavioral expressions. There are, however, notable exceptions. For example, working within a costly signaling framework, Bulbulia has argued that ritual behavior ratifies beliefs in supernatural agents which in and of themselves cannot evolve without reliable mechanisms for the communication of these beliefs (i.e., ritual 
behavior) (Bulbulia 2004a; 2004b). Conversely, Johnson and Bering (2006) have argued that the cross-cultural prevalence of a fear of supernatural punishment is an adaptation that enabled the inhibition of self-interested behavior, and hence the avoidance of punishment by fellow group members. In ancestral environments, in other words, those individuals who feared supernatural punishment were better able to cultivate the benefits of cooperation with other group members, and so a propensity to believe in supernatural punishment spread throughout human populations.

Finally, others who employ an adaptationist approach have focused on how religion may support reproductive success directly. For example, some have argued that the advertisement of religious traits to potential mates communicates preferences for stable monogamous pair bonds and high-fertility mating strategies (Slone 2006; Blume 2010; Bulbulia et al. 2015; Shaver 2017). Still others have focused on how religion and rituals can be used by men to avoid cuckoldry and increase paternity certainty, at the expense of female interests (Strassmann 1992; 1996; Boster et al. 1998; Strassmann et al. 2012). Regardless of the particular fitness problems they address, adaptationist models each face the key challenge of identifying the actual phenotypes, or clusters of phenotypes, resulting from selection pressures that constitute "religion" (Powell and Clarke 2008). This is no simple matter, however, since there is no agreement on a definition of religion (Smith 1992; Asad 1993).

\section{RELIGION, PRETENSE, AND INSTITUTIONAL COGNITION}

The three approaches surveyed thus far account for many of religion's salient features, but they leave key questions unresolved. If belief in gods and spirits is a spontaneous product of natural human cognition-whether byproduct or functional adaptation - why do religions so often require their adherents to ritually demonstrate their beliefs? That is, why are religious beliefs so apparently dependent on, and sanctioned by, cultural norms (Geertz 1973)? Moreover, if unfalsifiable supernatural beliefs motivate and stabilize ritual participation, why do those beliefs consistently converge on supernatural agent concepts-in other words, why does agent cognition specifically seem to recur as a central feature of ritual, when other unfalsifiable claims might just as easily motivate ritual performance and group commitments?

In our view, the fact that religious beliefs and practices are nearly always the targets of normative social pressure suggests that spontaneous mental processes may not be the first place to look for the modular origins of religion. Rather, the cognitive processes that undergird religious beliefs and behaviors may be similar to those that support norms, rules, and conventional behavior-in other words, those that make institutions possible (Searle 1995). These processes specifically include what Taves (2015) has called "pretense," or the ability to entertain distinct-even opposingcognitive representations simultaneously. For example, the scenery does not change when we drive across Massachusetts into Vermont, yet we "know" they are different states. Likewise, a believer may mentally represent a spiritual presence during prayer, although her physical surroundings do not change (Schjødt et al. 2009). In other words, religious beliefs are examples of what philosopher John Searle (1995) calls "institutional facts"-propositions that people treat as true, but which derive from shared social agreements. Institutional facts are contrasted with "brute facts," which do not depend on shared human agreements (such as the existence of clouds or rocks, which would exist whether or not humans were around to observe them).

Importantly, institutional facts such as invisible states or invisible spirits are deeply shaped by cultural authorities, which instruct people in the "correct" way to imagine them, and are thus inherently normative. This observation 
parallels Van Leeuwen's (2014) insight that religious beliefs are cognitively different from other types of belief in that they are susceptible to special authority, govern behavior only in limited domains, and constitute social identity, among other features. The belief that gravity pulls objects toward the earth, for example, could not be constitutive of any social identity, because it holds true everywhere across the planet; only unfalsifiable or difficult-to-verify beliefs are capable of serving as group identity markers (Simler and Hanson 2017). Such arguments correspond with Horton's (1967) observation that traditional religious beliefs are remarkably insulated from counter-evidence, despite resting on the same cognitive foundations as other beliefs. However, the construal of religious beliefs as "cognitive pretense" diverges from evolutionary byproduct accounts precisely in locating the primary origin of religious beliefs not in immediate, first-order perceptions or biased intuitions, but rather in second-order representations that are overlaid on top of perceptual data.

The supposition that religious beliefs emerge from the same cognitive processes that generate institutional facts helps make sense of the well-documented association between religiousness and cultural conservatism, since conservatism emphasizes adherence to norms and obedience to cultural authority (McClosky 1958; Unger 2007; Haidt 2012; Sibley and Bulbulia 2014). Obeying institutional norms and participating in ritual both have affinities with pretense, or acting out "the way things ought to be in conscious tension to the way things are" (Smith 1992, 109; see also Rakoczy 2008). The fact that both religiousness and conservatism emphasize behavioral standards embedded in abstract templates implies that, when it comes to institutional facts and religious concepts alike, ritual comes before belief (Sosis 2003; Bellah 2011). For example, rather than experiencing spontaneous religious intuitions, charismatic Christians of some denominations consciously "work" to generate experiences of
God by setting aside time to imagine conversing with him, as directed by spiritual advisers and church leaders (Luhrmann 2012).

\section{THE ROLE OF LANGUAGE IN INSTITUTIONS}

We propose, then, that the evolution of religion is best addressed from the standpoint that religious cognitions and behaviors are not qualitatively different from those that underlie other human institutions. Indeed, religion and the other institutions that form "culture" may be simply different instances of the same basic social-cognitive kind (Luckmann 1967; Bloch 2008). All institutions, including religions, depend on cognitive representations of norms and roles that are not based in immediate empirical facts (Searle 1995). In short, all institutions rely on pretense. Meanwhile, pretense, in the sense meant by Taves (2015), is fundamentally linguistic. The capacity of symbolic language to generate abstract ideas via the novel recombination of perceptual experience and other cognitive content underlies our capacity to imagine alternative realities and to share them with one another (Dor 2015). Moreover, unlike nonlinguistic communication, such as ritualized animal signals, language also enables the representation of past and future states, which by definition are not immediately present (Bellah 2011). Hence, language makes possible conceptual abstractions such as "the tribe existed before me and will exist after I am gone" or "the ancestors exist even if I can't see them." Human social life therefore depends on conditioned imagination in a way that could not be true of any animal, no matter how complex, that lacked symbolic language (Bloch 2008).

Moreover, as indicated above, institutional facts are also fundamentally deontic. This means their existence depends on norms and sanctioned behaviors (Searle 1995). In turn, deontic norms fundamentally require the representation of possible worlds and so depend on imaginative acts (Jensen 2013). Massachusetts and Vermont only exist because millions of people 
behave as if they existed-filing the correct tax forms, observing different laws on each side of the border, etc. These behaviors are normative, or obligatory. Importantly, because language enables people to mentally represent such norms in abstraction from any concrete surroundings, the norms that define institutional facts generally persist for longer than the individual people who enter and exit the institutions (Bloch 2008). Thus, both Massachusetts and Vermont have "outlived" generations of particular inhabitants, continuing to persist institutionally despite the change in the makeup of their populations.

Although he does not use Searle's terminology, Maurice Bloch (2008; 2016) deploys a similar line of reasoning to argue for the cognitive continuity of religion with other human institutions. Like other institutional facts, religious propositions depend on the pretense of alternate realities that are not reducible to immediate, physical affordances, but which instead exist in an abstract mental space he terms the "transcendental social." By "transcendental," Bloch simply means dependent on mental representations that are reproduced and maintained by social transmission and are thus more stable than physical realities. The ability to imagine transcendental social roles is why people in small-scale societies may, for example, treat an elder with respect and deference even though he is senile-namely, in certain contexts the role is more important than the physical person (Bloch 2008). Bloch contrasts the transcendental social with the "transactional social," or relationships that are based on brute facts such as relative strength. Chimpanzees have only transactional social structures, since status in their hierarchies generally boils down to who would be likely to win a confrontation. Lacking language, chimpanzees cannot imagine differentiated, long-lasting social roles with finely graded conceptual distinctions.

Bloch asserts, then, that the capacity to imagine transcendental social relations enables the remarkable differentiation and complex internal structuring of human societies along lines that have no physical basis, such as moieties or fictive kin groups. This observation is relevant because recent cognitive and evolutionary approaches to religion have tended to overlook the importance of differentiated social structure for understanding religion's functions (Smaldino 2014). Moreover, it does not take very many steps beyond "moiety" to arrive at phenomena that seem distinctly religious, since the maintenance and legitimization of subgroups such as moieties depends on cultural ritual (White 1981). Unlike animal ritualization, human ritual includes symbolic or representational content and thus can refer to constructs or ideals that are not immediately present or visible, such as moieties or other roles or groups (Rappaport 1999).

\section{THE ROLE OF SUPERNATURAL AGENTS IN RELIGIOUS AND INSTITUTIONAL COGNITION}

Let us now extend our argument to provide a more detailed picture of the emergence of the supernatural in human evolution. Along with Bloch, we suggest that gods, spirits, and transcendental social roles all comprise institutional facts, and are all of a single cognitive kind. Once humans started using language and ritual to generate "imagined communities" (Anderson 1991) such as extended clans or moieties, ancestors and the yet-to-be-born logically emerged as equally eligible for membership in those groups, since they were no more invisible than, say, distant clansmen living across the mountains. That is, individual mental representations of the social group came to include its past and future inhabitants, neither of whom are immediately visible. Something very similar, Bloch argues, was true of gods and spirits, which were, and are, simply additional transcendental social roles.

Thus, when humans became able to imaginatively construct invisible group identities and roles and to allow the dead to inhabit them, a cognitive dam burst. Suddenly, no logical barrier 
stood against extending group membership and role privileges to beings who not only no longer existed physically, but in fact had never physically existed. Reciprocally, the effusion of ascribed invisible roles — husband, wife, moiety member, elder, initiate - made it logically possible to imagine and then treat seriously novel institutional roles that could not, at least normally, be inhabited by living persons. That is, the extension of transcendental sociality beyond that which was currently embodied, combined with the generation of imagined beings who nonetheless possessed social status and group identity, led inexorably to the dissolution of any barriers against social identities that in principle lacked the possibility (or at least necessity) of being embodied. This process of cognitive slippage and expansion implies, as Bloch argues, that "the transcendental social and phenomena that we have ethnocentrically called religion are part and parcel of a single unity" (2008, 2057; see also Sosis and Kiper 2014).

The evolutionary emergence of supernatural agents may thus be best explained by our propensity for using language and ritual to generate institutional facts and social roles that are separable from concrete persons: simply put, supernatural agents are sub-personal institutional "roles" that do not require embodiment. That some supernatural roles can be embodied, for example during possession trance in Haitian Vodou or Korean shamanism (Bourguignon 1976; Harvey 1979), or incarnated, such as with Jesus in Christianity or Vishnu's various avatars in Hinduism, is not a refutation of this claim. Namely, we argue only that the social-cognitive etiology of beliefs in gods and spirits emerges from the separability of role concepts and actual persons, such that social roles can be entertained and recognized even if they typically do not or never have incumbents.

Yet why would these non-embodied roles receive the special (and costly) ritual treatment they do, and why do they become so centrally located in people's mental schemata of the social environment? That is, what distinguishes gods from other kinds of institutional facts? First, following previous writers (Rappaport 1999; McCauley and Lawson 2002), we suggest that the unfalsifiable nature of supernatural roles is precisely what earns their central position in humans' cognitive schemata. Specifically, ritual that is directed toward beings that are both (1) unfalsifiable and (2) sacred is ideally suited to stabilizing contingent and contextually relative social norms, because it displaces the most central obligations in the moral matrix onto positions that depend wholly on institutional conventions for their existence, and which therefore cannot be subjected to utilitarian treatment (Rappaport 1999). A person who takes her ritual obligations seriously, then, tautologically demonstrates acceptance of the norms that define her social group (Rappaport 1999; Morgan, Wood, and Caldwell-Harris 2018).

Second, because gods and spirits are represented as intentional agents, they are cognitively suited to serve as targets of normative obligations. Yet because these agents, lacking embodiment, cannot provide the same actual strategic benefits to interactants that embodied persons can, the various obligations that people owe to them tend to slip out of the reach of utilitarian cost-benefit calculations. The resulting sanctification of core social obligations renders the entire moral system more stable (Rappaport 1999; Purzycki and Sosis 2013). In other words, non-embodied transcendental social roles-gods and spirits-serve an anchoring function in the cognitive representation of moral schemata. Moreover, because they have no concrete referents, gods and spirits cannot empirically threaten institutional norms in the way that real people do when they conspicuously fail to live up to normative standards (Bloch 2008). We suggest, then, that the non-embodied nature of gods and other wholly transcendental entities serves to inculcate a general deontological stance toward the social obligations that characterize a social group. Importantly, we do not mean to imply that people do not treat gods in a transactional manner, since exchanging favors is a common 
feature of interactions with gods. Rather, we are arguing that, in comparison to relations between people, relations with gods and spirits simply tend to emphasize the deontological element above the transactional element. It follows, then, that gods and sacred spirits specifically tend to drift toward the conceptual center of any transcendental social scheme. While other unfalsifiable beliefs may serve as group identity markers or play an important role in ritual performance (Purzycki and Sosis 2010), only agent-like transcendental roles can motivate a deontological stance toward social obligations. It is in this capacity that supernatural concepts are distinct from other kinds of institutional or socially constructed facts, although all institutional facts share the same cognitive scaffolding.

What evidence exists in favor of the institutional cognition model of religion? As discussed above, the fact that ideological conservatism, conventionality, and religiosity are highly statistically correlated constitutes credible prima facie evidence for the posited model. Religious commitments, moral conventions, and secular cultural authorities or identities all share a common root: they are socially constructed institutions, dependent on contingent agreements, not brute facts, for their functioning. It may be, then, that some cognitive profiles are simply more conducive to dealing in institutional facts than others. Cultural liberalism and irreligiosity, by contrast, are both associated with one another and with individualism and analytical thought (Bainbridge 2005; Caldwell-Harris 2012). It stands to reason that individualistic, analytical minds may be corrosive to truth claims that depend, by definition, on cultural agreement and authoritative social norms. What analytically minded individualists want is truth claims that can be verified without referencing the social manifold - that is, they want brute facts.

Thus, the institutional cognition model of religion makes sense of the ways in which religious beliefs do not seem to be commensurable with other kinds of belief (Van Leeuwen 2014).
Specifically, religious beliefs depend substantially on special authority and are typically not vulnerable, or even subjected, to the same empirical or skeptical treatment as other, more prosaic beliefs (McPhetres and Zuckerman 2017). It is as if religious claims were "insulated" from counter-evidence-and indeed, they are (Horton 1967). All institutional facts depend on a certain base level of a priori credulity. If everyone denied that Vermont really exists, it would indeed stop existing. The same does not hold true of gravity. Institutional facts, then, fundamentally need insulation from excessive analytical reflection and so depend on normative coercion to survive. This dependence also explains why exposure to CREDs accounts for far more variation in religiousness than do individual differences in cognitive biases (Willard and Cingl 2017). Religious beliefs are second-order products of institutional cognition that depend on special authority to index social norms, and so they cannot be usefully analyzed in isolation from socialization or ritual performance.

\section{CONCLUSION}

Over the past three decades, cognitive and evolutionary approaches have made enormous strides in charting the origins of religious phenomena. Byproduct theories have shed light on the relationship between religious beliefs and cognitive tendencies such as anthropomorphic biases, while cultural evolutionary models helped reconcile massive cultural variations in religious beliefs and rituals with their apparent convergent functionality. Meanwhile, adaptationist accounts make sense of seeming paradoxes in religious behavior and belief, such as the apparent wastefulness of costly rituals and unfalsifiable beliefs. Yet cognitive byproduct and cultural evolutionary theories only partially explain why religious beliefs_-supposedly emerging from and transmitted via innate cognitive predispositions-require such high levels of normative cultural enforcement to be sustained. Adaptationist theories, by contrast, 
have not successfully articulated why supernatural agent concepts specifically-as opposed to supernatural concepts in general (e.g., Purzycki and Sosis 2010)_attain the centrality they do in cultural systems, or-in the case of supernatural punishment hypotheses (Johnson 2016) have tended to oversimplify the functions of supernatural agents. Here, we have attempted to augment these accounts of the cognitive foundations of religious phenomena by focusing attention on the role of human language in enabling the generation and transmission of institutional concepts whose truth conditions are not met by sheer physical facts. In doing so, we highlight the continuity between religions and other forms of institutional life.

Following Maurice Bloch, we argue that there is no strict category distinction between the cognitive processes that enable the representation of extra-empirical or institutional propositions ("This is the state border") and those that enable representations of religious propositions ("God is three in one"). Both are grounded in the capacity of language to recombine perceptual experience and conceptual content in novel forms that are not constrained by, or reducible to, immediate physical facts, as well as to serve as a medium that reliably conveys these novel representations between people. By describing religious beliefs as emerging from complex social cognition rather than directly from intra-individual cognitive processes, this account diverges from theories that describe religious beliefs as emerging from intuitive defaults. Yet, by locating the roots of religious concepts in the species-general capacity for language and "pretense," we also affirm that religion is, indeed, "natural" (McCauley 2013).

Of course, the capacity for institutional cognition allows humans to generate many kinds of concepts: jurisdictional borders, money, rules of dynastic succession. Why, then, are gods and spirits so common across cultures? More specifically, why are gods and spirits so often implicated in cultural rituals? We believe that previous attempts to directly address this question using cognitive frameworks (e.g., McCauley and Lawson 2002) have overemphasized the role of explanatory motives and causal inference in driving supernatural agent beliefs. Rather, gods populate rituals because such contexts are fundamentally evocative of social roles and norms, and only agents can be the targets of these deontic attributes. As discussed above, then, imaginative representations of anthropomorphic gods and spirits are uniquely well suited to stabilizing systems of extra-empirical social roles and norms, because only agents who cannot actually provide their interaction partners with tangible benefits can enforce the deontic principles irrespective of those partners' utilitarian motivations. As a result, imaginative repertoires invariably tend to gravitate toward shared representations of person-like agents with whom interactants can only have deontic relations.

Thus, our evolved cognitive architecture does indeed constrain religious cognition to conform to intuitive anthropomorphic expectations, as byproduct theorists have often argued, but that architecture does not directly lead to religious cognitions spontaneously or directly in a first-order sense. Religious beliefs and practices are also largely functional, as adaptationists claim, in the sense that they anchor and stabilize systems of empirically unprovable norms and culturally variable institutions that enable complex coordination within human groups. Indeed, as Sosis and Kiper (2014) emphasize, in human evolutionary history norms and religious institutions probably emerged interdependently. However, the characteristic features of religious cognition are not necessarily direct evolutionary adaptations, but rather logically natural, even mechanically necessary, responses to specific strategic pressures of using language to generate culturally variable institutional facts based on deontic norms.

The institutional cognition model of religion therefore does not repudiate previous evolutionary and cognitive frameworks for studying religion. Instead, it reconciles them 
while offering novel insights, including clearer understanding of the relationship between religiosity and conservatism and better purchase on the role of religion in maintaining differentiated social structures, such as moieties, gender roles, and legitimate versus illegitimate authorities. The proposed model therefore offers strong continuity with previous theories while addressing several of their problematic features, and moving beyond the byproduct-adaptationist dichotomy. The institutional cognition model of the evolution of religion may thus benefit future research by providing a cognitive framework for investigating phenomena—such as fictive group structuring and imaginal pretense-that are often considered highly relevant for religion, but which have previously typically been the province of sociologists or social theorists rather than cognitive scientists. Religion is a vital dimension of human affairs, but its explanation is neither quite as simple nor as complex as we have supposed. Rather than being either a mere spandrel or a dedicated functional adaptation-religion is, in different contexts, both—it is also what naturally emerges when intelligent, highly social animals evolve the remarkable capacity for symbolic thinking and cultural transmission, and therefore gain the ability to generate alternative worlds that must be coordinated between individuals.

\section{ACKNOWLEDGMENTS}

This project emerged out of a presentation delivered at a conference in Santa Ana Pueblo, New Mexico, on the evolution of religion, in November 2017. The authors wish to thank Jay Feierman for spearheading the organization of that conference. We acknowledge a great debt to Roy D'Andrade for introducing us (through his mentorship of Shaver) to Searle's work. During the preparation of this paper, Wood was primarily supported by a grant from the John Templeton Foundation (grant \#61035). The authors also wish to acknowledge partial support from the University of Otago (grant \#114172.01.S.CA DRG17) and the Society for Personality and Social Psychology.

\section{WORKS CITED}

Abbot, Patrick, Jun Abe, John Alcock, Samuel Alizon, Joao A. C. Alpedrinha, Malte Andersson, Jean-Baptiste Andre, et al. 2011. "Inclusive Fitness Theory and Eusociality." Nature 471 (7339): E1-4. doi:10.1038/nature09831.

Alcorta, Candace S., and Richard Sosis. 2005. "Ritual, Emotion, and Sacred Symbols: The Evolution of Religion as an Adaptive Complex." Human Nature 16 (4): 323-59. doi:10.1007/s12110-005-1014-3.

Anderson, Benedict. 1991. Imagined Communities: Reflections on the Origin and Spread of Nationalism. New York: Verso.

Asad, Talal. 1993. Genealogies of Religion: Discipline and Reasons of Power in Christianity and Islam. Baltimore: Johns Hopkins University Press.

Atran, Scott. 2002. In Gods We Trust: The Evolutionary Landscape of Religion. Oxford: Oxford University Press.

Atran, Scott, and Jeremy Ginges. 2012. "Religious and Sacred Imperatives in Human Conflict." Science 336 (6083): 855-57. doi:10.1126/science.1216902.

Atran, Scott, and Joseph Henrich. 2011. "The Evolution of Religion: How Cognitive Byproducts, Adaptive Learning Heuristics, Ritual Displays, and Group Competition Generate Deep Commitments to Prosocial Religions." Biological Theory 5 (1): 18-30. doi:10.1162/BIOT_a_00018.

Bainbridge, William. 2005. "Atheism." Interdisciplinary Journal of Research on Religion 1: 1-26.

Banerjee, Konika, and Paul Bloom. 2014. "Why Did This Happen to Me? Religious Believers' and Non-Believers' Teleological Reasoning about Life Events." Cognition 133 (1):277-303. doi:10.1016/j.cognition.2014.06.017.

Barkow, Jerome H., Leda Cosmides, and John Tooby, eds. 1995. The Adapted Mind: Evolutionary Psychology and the Generation of Culture. Reprint edition. New York: Oxford University Press.

Barrett, Justin L., and F. C. Keil. 1996. "Conceptualizing a Nonnatural Entity: Anthropomorphism in God Concepts." Cognitive Psychology 31 (3): 219-47. doi:10.1006/cogp.1996.0017. 
Barrett, Justin. 2000. "Exploring the Natural Foundations of Religion." Trends in Cognitive Sciences 4 (1): 29-34. doi: 10.1016/s1364-6613(99)01419-9.

2004. Why Would Anyone Believe in God? Walnut Creek, CA: AltaMira Press.

Barrett, Justin L., and Jonathan A. Lanman. 2008. "The Science of Religious Beliefs" 38 (2): 109-124.

Barrett, Justin, and Melanie Nyhof. 2001. "Spreading Non-Natural Concepts: The Role of Intuitive Conceptual Structures in Memory and Transmission of Cultural Materials." Journal of Cognition and Culture 1 (1): 69-100. doi:10.1163/156853701300063589.

Bellah, Robert Neelly. 2011. Religion in Human Evolution: From the Paleolithic to the Axial Age. Cambridge: Belknap Press of Harvard University Press.

Berger, Peter Ludwig. 1969. The Sacred Canopy: Elements of a Sociological Theory of Religion. Garden City: Anchor Books.

Berns, Gregory S., Emily Bell, C. Monica Capra, Michael J. Prietula, Sara Moore, Brittany Anderson, Jeremy Ginges, and Scott Atran. 2012. "The Price of Your Soul: Neural Evidence for the Non-Utilitarian Representation of Sacred Values." Philosophical Transactions of the Royal Society of London. Series B, Biological Sciences 367 (1589): 754-62. doi:10.1098/rstb.2011.0262.

Bidney, David. 1944. "On the Concept of Culture and Some Cultural Fallacies." American Anthropologist 46 (1): 30-44. Bloch, Maurice. 2008. "Why Religion Is Nothing Special but Is Central." Philosophical Transactions of the Royal Society B: Biological Sciences 363 (1499): 2055-61. doi:10.1098/rstb.2008.0007.

2016. "Imagination from the Outside and from the Inside." Current Anthropology 57 (S13): S80-87. doi:10.1086/685496.

Bloom, Paul. 2005. Descartes' Baby: How the Science of Child Development Explains What Makes Us Human. Export edition. New York: Basic Books.

Blume, Michael. 2010. "Von Hayek and the Amish Fertility: How Religious Communities Manage to Be Fruitful and Multiply. A Case Study." In The Nature of God: Evolution and Religion, edited by Ulrich Frey, 159-75. Marburg: Tectum Verlag.

Boster, James S., Richard R. Hudson, and Steven J. C. Gaulin. 1998. "High Paternity Certainties of Jewish Priests." American Anthropologist 100 (4): 967-71. doi:10.1525/aa.1998.100.4.967.

Botero, Carlos A., Beth Gardner, Kathryn R. Kirby, Joseph Bulbulia, Michael C. Gavin, and Russell D. Gray. 2014. "The Ecology of Religious Beliefs." Proceedings of the National Academy of Sciences 111 (47): 16784-89. doi:10.1073/pnas.1408701111.

Bourguignon, Erika. 1976. Possession. San Francisco, CA: Chandler \& Sharp.

Boyd, Robert, and Peter J. Richerson. 1988. Culture and the Evolutionary Process. Chicago: University of Chicago Press.

Boyer, Pascal. 1994. The Naturalness of Religious Ideas: A Cognitive Theory of Religion. Berkeley, CA: University of California Press.

2001. Religion Explained: The Evolutionary Origins of Religious Thought. New York: Basic Books.

Boyer, Pascal, and Pierre Liénard. 2006. "Why Ritualized Behavior? Precaution Systems and Action Parsing in Developmental, Pathological and Cultural Rituals." The Behavioral and Brain Sciences 29 (6): 595-613; discussion 613-50.

Boyer, Pascal, and Charles Ramble. 2001. “Cognitive Templates for Religious Concepts: Cross-Cultural Evidence for Recall ofCounter-Intuitive Representations."CognitiveScience 25 (4):535-64.doi:10.1207/s15516709cog2504_2.

Bulbulia, Joseph. 2004. "The Cognitive and Evolutionary Psychology of Religion." Biology and Philosophy 19 (5): 655-86. doi:10.1007/s10539-005-5568-6.

2004. "Religious Costs as Adaptations That Signal Altruistic Intention." Evolution and Cognition 10 (1): 9-38.

2008."Meme Infection or Religious Niche Construction? An Adaptationist Alternative to The Cultural Maladaptationist Hypothesis." Method \& Theory in the Study of Religion 20 (1):67-107. doi:10.1163/157006808X260241.

Bulbulia, Joseph, John Shaver, Lara M. Greaves, Sosis, Richard, and Chris G. Sibley. 2015. “Religion and Parental Cooperation: An Empirical Test of Slone's Sexual Signaling Model." In The Attraction of Religion: A Sexual Selectionist Account, edited by D. Jason Slone and James A. Van Slyke, 29-62. London: Bloomsbury. 
Caldwell-Harris, Catherine L. 2012. “Understanding Atheism/Non-Belief as an Expected Individual-Differences Variable." Religion, Brain \& Behavior 2 (1): 4-23. doi:10.1080/2153599X.2012.668395.

Davis, Taylor. 2015. "Group Selection in the Evolution of Religion: Genetic Evolution or Cultural Evolution?" Journal of Cognition and Culture 15 (3-4): 235-53. doi:10.1163/15685373-12342149.

Dor, Daniel. 2015. The Instruction of Imagination: Language as a Social Communication Technology. Oxford: Oxford University Press.

Durkheim, Émile. [1912] 2008. The Elementary Forms of Religious Life. Oxford, England: Oxford University Press. Evans, Jonathan St. B.T. 2010. Thinking Twice: Two Minds in One Brain. Oxford: Oxford University Press.

Fodor, Jerry A. 1983. The Modularity of Mind: An Essay on Faculty Psychology. Cambridge, Mass: A Bradford Book / MIT Press.

Geertz, Clifford. 1973. The Interpretation Of Cultures. New York: Basic Books.

Gervais, W., and J. Henrich. 2010. "The Zeus Problem: Why Representational Content Biases Cannot Explain Faith in Gods." Journal of Cognition and Culture 10 (3-4): 383-89. doi: 10.1163/156853710x531249.

Gervais, Will M., Aiyana K. Willard, Ara Norenzayan, and Joseph Henrich. 2011. "The Cultural Transmission of Faith: Why Innate Intuitions Are Necessary, but Insufficient, to Explain Religious Belief." Religion 41 (3): 389-410. doi:0.1080/0048721X.2011.604510.

Ginges, Jeremy, and lan Hansen. 2010. "Religious Belief, Coalitional Commitment, and Support for Suicide Attacks." Evolutionary Psychology: An International Journal of Evolutionary Approaches to Psychology and Behavior 8 (3): 346-49. doi: 10.1177/147470491000800303.

Gómez, Ángel, Lucía López-Rodríguez, Hammad Sheikh, Jeremy Ginges, Lydia Wilson, Hoshang Waziri, Alexł andra Vázquez, Richard Davis, and Scott Atran. 2017. "The Devoted Actor's Will to Fight and the Spiritual Dimension of Human Conflict." Nature Human Behaviour 1 (9): 673-79. doi:10.1038/s41562-017-0193-3.

Grafen, Alan. 1990. “Biological Signals as Handicaps.” Journal of Theoretical Biology 144 (4):517-46. doi:10.1016/ S0022-5193(05)80088-8.

Guthrie, Stewart Elliott. 1995. Faces in the Clouds: A New Theory of Religion. New York: Oxford University Press.

Haidt, Jonathan. 2012. The Righteous Mind: Why Good People Are Divided by Politics and Religion. New York: Pantheon.

Harmon-Vukić, Mary, M. Afzal Upal, and Kelly J. Sheehan. 2012. “Understanding the Memory Advantage of Counterintuitive Concepts." Religion, Brain \& Behavior 2 (2): 121-39. doi:10.1080/2153599X.2012.672816.

Harvey, Youngsook Kim. 1979. Six Korean Women: The Socialization of Shamans. First Edition edition. St. Paul: West Group.

Henrich, Joseph. 2009. "The Evolution of Costly Displays, Cooperation and Religion: Credibility Enhancing Displays and Their Implications for Cultural Evolution." Evolution and Human Behavior 30 (4): 244-60. doi:10.1016/j.evolhumbehav.2009.03.005.

Henrich, Joseph, and Francisco J Gil-White. 2001. "The Evolution of Prestige: Freely Conferred Deference as a Mechanism for Enhancing the Benefits of Cultural Transmission." Evolution and Human Behavior 22 (3): 165-96. doi:10.1016/S1090-5138(00)00071-4.

Horton, Robin. 1967. "African Traditional Thought and Western Science. Part I. From Tradition to Science." Africa: Journal of the International African Institute 37 (1): 50-71. doi:10.2307/1157195.

Hume, David. [1779] 2007. Dialogues Concerning Natural Religion: And Other Writings. Cambridge, UK; New York: Cambridge University Press.

lannaccone, Laurence. 1994. “Why Strict Churches Are Strong." American Journal of Sociology 99 (5): 1180-211. doi: $10.1086 / 230409$.

Irons, William. 2001. "Religion as a Hard-to-Fake Sign of Commitment." In Evolution and the Capacity for Commitment, 290-309. Volume III in the Russell Sage Foundation Series on Trust. New York: Russell Sage Foundation.

Jensen, Jeppe Sinding. 2013. "Normative Cognition in Culture and Religion." Journal for the Cognitive Science of Religion 1 (1): 47-70.

Johnson, Dominic. 2016. God Is Watching You: How the Fear of God Makes Us Human. New York: Oxford University Press. 
Johnson, Dominic, and Jesse Bering. 2006. "Hand of God, Mind of Man: Punishment and Cognition in the Evolution of Cooperation." Evolutionary Psychology 4: 219-33.

Johnson, Dominic D. P. 2005. "God's Punishment and Public Goods." Human Nature 16 (4): 410-46. doi:10.1007/ s12110-005-1017-0.

Kahneman, Daniel. 2013. Thinking, Fast and Slow. New York: Farrar, Straus and Giroux.

Kelemen, Deborah. 2004. "Are Children 'Intuitive Theists'? Reasoning about Purpose and Design in Nature." Psychological Science 15 (5): 295-301. doi:10.1111/j.0956-7976.2004.00672.x.

Laland, Kevin N., and Gillian R. Brown. 2002. Sense and Nonsense: Evolutionary Perspectives on Human Behaviour. New York: Oxford University Press.

Lanman, Jonathan A., and Michael D. Buhrmester. 2017. "Religious Actions Speak Louder than Words: Exposure to Credibility-Enhancing Displays Predicts Theism." Religion, Brain \& Behavior 7 (1): 3-16. doi:10.1080 /2153599X.2015.1117011.

Lawson, E. Thomas, and Robert N. McCauley. 1993. Rethinking Religion: Connecting Cognition and Culture. Cambridge: Cambridge University Press.

Luckmann, Thomas. 1967. The Invisible Religion: The Problem of Religion in Modern Society. First. London: MacMillan Publishing Company.

Luhrmann, T. M. 2012. When God Talks Back: Understanding the American Evangelical Relationship with God. Reprint edition. New York: Vintage.

Maij, David. L. R., Frenk van Harreveld, Will Gervais, Yann Schrag, Christine Mohr, and Michiel van Elk. 2017. "Mentalizing Skills Do Not Differentiate Believers from Non-Believers, but Credibility Enhancing Displays Do." PLOS ONE 12 (8). doi:10.1371/journal.pone.0182764.

Maynard Smith, John, and David Harper. 2004. Animal Signals. New York: Oxford University Press.

McCauley, Robert N. 2013. Why Religion Is Natural and Science Is Not. New York: Oxford University Press.

McCauley, Robert N., and E. Thomas Lawson. 2002. Bringing Ritual to Mind: Psychological Foundations of Cultural Forms. Cambridge, UK; New York: Cambridge University Press.

McClosky, Herbert. 1958. "Conservatism and Personality." The American Political Science Review 52 (1): 27-45.

McNamara, Patrick, Richard Sosis, and Wesley J. Wildman. 2011."Announcing a New Journal: Religion, Brain \& Behavior." Religion, Brain \& Behavior 1 (1): 1-4. doi:10.1080/2153599X.2011.558704.

McPhetres, Jonathon, and Miron Zuckerman. 2017. "Religious People Endorse Different Standards of Evideni ce When Evaluating Religious Versus Scientific Claims." Social Psychological and Personality Science 8 (7): 836-42. doi:10.1177/1948550617691098.

Mogan, Reneeta, Ronald Fischer, and Joseph A. Bulbulia. 2017. “To Be in Synchrony or Not? A Meta-Analysis of Synchrony's Effects on Behavior, Perception, Cognition and Affect." Journal of Experimental Social Psychology 72 (September): 13-20. doi:10.1016/j.jesp.2017.03.009.

Morgan, Jonathan, Connor Wood, and Catherine Caldwell-Harris. 2018. "Reflective Thought, Religious Belief, and the Social Foundations Hypothesis." In The New Reflectionism in Cognitive Psychology: Why Reason Matters, edited by Gordon Pennycook, 10-32. Current Issues in Thinking and Reasoning. Abingdon: Routledge.

Murray, Michael J., and Lyn Moore. 2009. "Costly Signaling and the Origin of Religion." Journal of Cognition and Culture 9 (3): 225-45. doi:10.1163/156770909X12489459066264.

Nietzsche, Friedrich Wilhelm. [1887] 1998. On the Genealogy of Morality. Translated by Maudemarie Clark and Alan J. Swensen. Indianapolis, IN: Hackett Publishing.

Norenzayan, Ara. 2013. Big Gods: How Religion Transformed Cooperation and Conflict. Princeton, NJ: Princeton University Press.

Norenzayan, Ara, Scott Atran, Jason Faulkner, and Mark Schaller. 2006.“Memory and Mystery: The Cultural Selection of Minimally Counterintuitive Narratives." Cognitive Science 30 (3):531-53. doi:10.1207/s15516709cog0000_68.

Norenzayan, Ara, Azim F. Shariff, Will M. Gervais, Aiyana K. Willard, Rita A. McNamara, Edward Slingerland, and Joseph Henrich. 2016. "The Cultural Evolution of Prosocial Religions." Behavioral and Brain Sciences 39. doi:10.1017/S0140525X14001356.

Nowak, Martin A., and Sarah Coakley, eds. 2013. Evolution, Games, and God: The Principle of Cooperation. Cambridge, Massachusetts: Harvard University Press. 
Nowak, Martin A., Corina E. Tarnita, and Edward O. Wilson. 2010. "The Evolution of Eusociality." Nature 466 (7310): 1057-62. doi:10.1038/nature09205.

Olson, Daniel V. A., and Paul Perl. 2001. "Variations in Strictness and Religious Commitment Within and Among Five Denominations." Journal for the Scientific Study of Religion 40 (4): 757-64. doi:10.1111/0021-8294.00090.

Pennycook, Gordon, Robert M. Ross, Derek J. Koehler, and Jonathan A. Fugelsang. 2016. "Atheists and Agnostics Are More Reflective than Religious Believers: Four Empirical Studies and a Meta-Analysis." PIOS One 11 (4): e0153039. doi:10.1371/journal.pone.0153039.

Powell, Russell, and Steve Clarke. 2012. "Religion as an Evolutionary Byproduct: A Critique of the Standard Model." The British Journal for the Philosophy of Science 63 (3): 457-86. doi:10.1093/bjps/axr035.

Power, Eleanor A. 2017. “Discerning Devotion: Testing the Signaling Theory of Religion." Evolution and Human Behavior 38 (1): 82-91. doi:10.1016/j.evolhumbehav.2016.07.003.

Premack, David, and G. Woodruff. 1978. "Does the Chimpanzee Have a Theory of Mind?" Behavioral and Brain Sciences 4 (4): 515-629.

Purzycki, Benjamin, and Richard Sosis. 2010. "Religious Concepts as Necessary Components of the Adaptive Religious System." In The Nature of God: Evolution and Religion, edited by Ulrich Frey, 37-59. Marburg: Tectum Verlag.

2013. "The Extended Religious Phenotype and the Adaptive Coupling of Ritual and Belief." Israel Journal of Ecology \& Evolution 59 (2): 99-108. doi:10.1080/15659801.2013.825433.

Purzycki, Benjamin Grant. 2010. “Cognitive Architecture, Humor and Counterintuitiveness: Retention and Recall of MCls." Journal of Cognition and Culture 10 (1): 189-204. doi:10.1163/156853710X497239.

Purzycki, Benjamin Grant, Coren Apicella, Quentin D. Atkinson, Emma Cohen, Rita Anne McNamara, Aiyana K. Willard, Dimitris Xygalatas, Ara Norenzayan, and Joseph Henrich. 2016. “Moralistic Gods, Supernatural Punishment and the Expansion of Human Sociality." Nature 530 (7590): 327-30. doi:10.1038/nature16980.

Purzycki, Benjamin Grant, and Aiyana K. Willard. 2016. "MCI Theory: A Critical Discussion." Religion, Brain \& Behavior 6 (3): 207-48. doi:10.1080/2153599X.2015.1024915.

Purzycki, M. D., Omar S. Haque, and R. Sosis. 2014. "Extending Evolutionary Accounts of Religion beyond the Mind: Religions as Adaptive Systems." In Evolution, Religion, and Cognitive Science: Critical and Constructive Essays, edited by FraserWatts and Léon P.Turner, 74-91. Oxford:Oxford University Press. doi:10.1093/acprof: oso/9780199688081.001.0001.

Rakoczy, Hannes. 2008. "Pretence as Individual and Collective Intentionality." Mind \& Language 23 (5): 499 517. doi:10.1111/j.1468-0017.2008.00357.x.

Rappaport, Roy A. 1999. Ritual and Religion in the Making of Humanity. Cambridge, UK; New York: Cambridge University Press.

Sanderson, S. 2008. "Adaptation, Evolution, and Religion." Religion 38: 141-56. doi: 10.1016/j.religion.2008.01.003.

Scheitle, Christopher P., and Roger Finke. 2008. "Maximizing Congregational Resources: Selection versus Production." Social Science Research 37 (3): 815-27. doi:10.1016/j.ssresearch.2007.10.001.

Schjødt, Uffe, Hans Stødkilde-Jørgensen, Armin W. Geertz, and Andreas Roepstorff. 2009. "Highly Religious Participants Recruit Areas of Social Cognition in Personal Prayer." Social Cognitive and Affective Neuroscience 4 (2): 199-207. doi:10.1093/scan/nsn050.

Searle, John R. 1995. The Construction of Social Reality. New York: Simon and Schuster.

Shariff, Azim F., Aiyana K. Willard, Teresa Andersen, and Ara Norenzayan. 2016. "Religious Priming: A Meta-Analysis with a Focus on Prosociality." Personality and Social Psychology Review 20 (1): 27-48. doi:10.1177/1088868314568811.

Shaver, John H. 2017. "Why and How Do Religious Individuals, and Some Religious Groups, Achieve Higher Relative Fertility?" Religion, Brain \& Behavior 7 (4): 324-27. doi:10.1080/2153599X.2016.1249920.

Shaver, John H., Geoffrey Troughton, Chris G. Sibley, and Joseph A. Bulbulia. 2016. "Religion and the Unmaking of Prejudice toward Muslims: Evidence from a Large National Sample." PLOS ONE 11 (3): e0150209. doi:10.1371/ journal.pone.0150209.

Shenhav, Amitai, David G. Rand, and Joshua D. Greene. 2012. "Divine Intuition: Cognitive Style Influences Belief in God." Journal of Experimental Psychology. General 141 (3): 423-28. doi:10.1037/a0025391. 
Sibley, Chris G., and Joseph A. Bulbulia. 2014. "How Do Religious Identities and Basic Value Orientations Affect Each Other Over Time?" The International Journal for the Psychology of Religion 24 (1): 64-76. doi:10.1080/ 10508619.2013.771600.

Simler, Kevin, and Robin Hanson. 2017. The Elephant in the Brain: Hidden Motives in Everyday Life. New York: Oxford University Press.

Slone, D. Jason. 2008. "The Attraction of Religion: A Sexual Selectionist Account." In The Evolution of Religion: Studies, Theories, and Critiques, edited by Joseph Bulbulia, Richard Sosis, Erica Harris, Cheryl Genet, and Karen Wyman, 181-87. Santa Margarita, CA: Collins Foundation Press.

Smaldino, Paul E. 2014. "The Cultural Evolution of Emergent Group-Level Traits." The Behavioral and Brain Sciences 37 (3): 243-54. doi:10.1017/S0140525X13001544.

Smith, Jonathan Z. 1992. To Take Place: Toward Theory in Ritual. Chicago, III.: University of Chicago Press.

Sober, Elliott, and David Sloan Wilson. 1999. Unto Others: The Evolution and Psychology of Unselfish Behavior. Cambridge, MA: Harvard University Press.

Soler, Montserrat. 2012. "Costly Signaling, Ritual and Cooperation: Evidence from Candomblé, an Afro-Brazilian Religion." Evolution and Human Behavior 33 (4): 346-56. doi:10.1016/j.evolhumbehav.2011.11.004.

Sosis, Richard. 2003. "Why Aren't We All Hutterites? : Costly Signaling Theory and Religious Behavior." Human Nature 14 (2): 91-127. doi:10.1007/s12110-003-1000-6.

2005. "Does Religion Promote Trust? The Role of Signaling, Reputation, and Punishment." Interdisciplinary Journal of Research on Religion 1: 1-30.

2009. "The Adaptationist-Byproduct Debate on the Evolution of Religion: Five Misunderstandings of the Adaptationist Program." Journal of Cognition and Culture 9 (3): 315-32. doi: 10.1163/156770909x125 18536414411.

2017. “The Road Not Taken: Possible Paths for the Cognitive Science of Religion." In Religion Explained? The Cognitive Science of Religion after Twenty-Five Years, edited by Luther H. Martin and Donald Wiebe, 155-67. London: Bloomsbury Publishing.

Sosis, Richard, and Eric R. Bressler. 2003. "Cooperation and Commune Longevity: A Test of the Costly Signaling Theory of Religion." Cross-Cultural Research 37 (2): 211-39. doi:10.1177/1069397103037002003.

Sosis, Richard, and Joseph Bulbulia. 2011. "The Behavioral Ecology of Religion: The Benefits and Costs of One Evolutionary Approach." Religion 41 (3): 341-62. doi:10.1080/0048721X.2011.604514.

Sosis, Richard, and Jordan Kiper. 2014. "Why Religion Is Better Conceived as a Complex System than a Norm-Enforcing Institution." The Behavioral and Brain Sciences 37 (3): 275-76. doi:10.1017/S0140525X13003038.

Sperber, Dan. 1985. On Anthropological Knowledge: Three Essays. Cambridge Cambridgeshire ; New York: Camb bridge University Press.

1996. Explaining Culture: A Naturalistic Approach. Oxford, UK ; Cambridge, Mass: Blackwell Publishers.

Sterelny, Kim. 2017.“Religion Re-Explained."Religion, Brain\&Behavior:1-20.doi:10.1080/2153599X.2017.1323779.

Strassmann, Beverly I. 1992. "The Function of Menstrual Taboos among the Dogon : Defense against Cuckoldry?" Human Nature 3 (2): 89-131. doi:10.1007/BF02692249.

1996. "Menstrual Hut Visits by Dogon Women: A Hormonal Test Distinguishes Deceit from Honest Signaling." Behavioral Ecology 7 (3): 304-15. doi:10.1093/beheco/7.3.304.

Strassmann, Beverly I., Nikhil T. Kurapati, Brendan F. Hug, Erin E. Burke, Brenda W. Gillespie, Tatiana M. Karafet, and Michael F. Hammer. 2012. "Religion as a Means to Assure Paternity." Proceedings of the National Academy of Sciences 109 (25): 9781-85. doi:10.1073/pnas.1110442109.

Talhelm, T., X. Zhang, S. Oishi, C. Shimin, D. Duan, X. Lan, and S. Kitayama. 2014. "Large-Scale Psychological Differences Within China Explained by Rice Versus Wheat Agriculture." Science 344 (6184): 603-8. doi:10.1126/science.1246850.

Taves, Ann. 2015. "Reverse Engineering Complex Cultural Concepts: Identifying Building Blocks of 'Religion."' Journal of Cognition \& Culture 15 (1/2): 191-216.

Turpin, Hugh, Marc Andersen, and Jonathan A. Lanman. 2018. “CREDs, CRUDs, and Catholic Scandals: Experimentally Examining the Effects of Religious Paragon Behavior on Co-Religionist Belief." Religion, Brain \& Behavior 0 (0): 1-13. doi:10.1080/2153599X.2018.1439087. 
Tylor, Edward Burnett. 1870. Researches Into the Early History of Mankind and the Development of Civilization. London: J. Murray.

Unger, Rhoda K. 2007. “Religious Ideology, a Neglected Variable." The American Psychologist 62 (9): 1076-77. doi:10.1037/0003-066X.62.9.1076.

Vail, Kenneth E, Zachary K Rothschild, Dave R Weise, Sheldon Solomon, Tom Pyszczynski, and Jeff Greenberg. 2010. "A Terror Management Analysis of the Psychological Functions of Religion." Personality and Social Psychology Review: An Official Journal of the Society for Personality and Social Psychology, Inc 14 (1): 84-94. doi:10.1177/1088868309351165.

Van Leeuwen, Neil. 2014. “Religious Credence Is Not Factual Belief." Cognition 133 (3): 698-715. doi:10.1016/j. cognition.2014.08.015.

Watts, Joseph, Simon J. Greenhill, Quentin D. Atkinson, Thomas E. Currie, Joseph Bulbulia, and Russell D. Gray. 2015. "Broad Supernatural Punishment but Not Moralizing High Gods Precede the Evolution of Political Complexity in Austronesia." Proc. R. Soc. B 282 (1804): 20142556. doi:10.1098/rspb.2014.2556.

White, Isobel. 1981. "Generation Moieties in Australia: Structural, Social and Ritual Implications." Oceania 52 (1): 6-27. doi:10.1002/j.1834-4461. 1981.tb01482.x.

Whitehouse, Harvey. 2004. Modes of Religiosity: A Cognitive Theory of Religious Transmission. Walnut Creek, CA: AltaMira Press.

Willard, Aiyana K. 2017. "Agency Detection Is Unnecessary in the Explanation of Religious Belief." Religion, Brain \& Behavior: 1-3. doi:10.1080/2153599X.2017.1387593.

Willard, Aiyana K., and Lubomír Cingl. 2017. "Testing Theories of Secularization and Religious Belief in the Czech Republic and Slovakia." Evolution and Human Behavior 0 (0). doi:10.1016/j.evolhumbehav.2017.01.002.

Willard, Aiyana K., and Ara Norenzayan. 2013. "Cognitive Biases Explain Religious Belief, Paranormal Belief, and Belief in Life's Purpose." Cognition 129 (2): 379-91. doi:10.1016/j.cognition.2013.07.016.

Wilson, David Sloan. 2002. Darwin's Cathedral: Evolution, Religion, and the Nature of Society. Chicago, Ill.: University Of Chicago Press.

Wilson, Edward O. 2013. The Social Conquest of Earth. New York: Liveright.

Wood, Connor P., Saikou Diallo, Wesley J. Wildman, and Justin Lane. Under review. "Why Does Religion Persist? Costly Signaling and Self-Regulation Drive Growth in a Dynamic Simulation of Religious Groups."

Xygalatas, Dimitris, Panagiotis Mitkidis, Ronald Fischer, Paul Reddish, Joshua Skewes, Armin W. Geertz, Andreas Roepstorff, and Joseph Bulbulia. 2013. "Extreme Rituals Promote Prosociality." Psychological Science, June. doi:10.1177/0956797612472910.

Zahavi, Amotz, and Avishag Zahavi. 1999. The Handicap Principle: A Missing Piece of Darwin's Puzzle. New York: Oxford University Press. 